\title{
El conocimiento geográfico de la Patagonia interior y la construcción de la imagen de Torres del Paine como patrimonio natural a conservar
}

Geographical knowledge of inner Patagonia and the configuration of Torres del Paine as a natural heritage to be preserved

\author{
Daniel Ferrer Jiménez*
}

\section{ANTECEDENTES}

Desde que en 1557 Juan Ladrillero, a bordo de la nao «San Luis», explorase la región marítima de Ultima Esperanza, con el propósito de extender la Gobernación de Chile hasta el extremo sur y tomar posesión del Estrecho de Magallanes, fueron muchos los navegantes que por una u otra razón surcaron los mares australes, recalando y desembarcando habitualmente en sus costas. Entre todos ellos se podría citar a Pedro Sarmiento de Gamboa, primer colonizador del Estrecho; a los británicos George Skyring y Kirke, teniente y piloto respectivamente de la nave «Adelaide», que recorrió los canales patagónicos en 1830, o a Robert Fitz Roy, capitán de la «Beagle», en la que viajó también el naturalista Charles Darwin. Todos ellos fueron hombres ilustres que contribuyeron activamente, con sus relatos, informes, cartas de navegación y otros documentos, al temprano conocimiento del territorio marítimo.

Sin embargo, el descubrimiento de la Patagonia interior no comenzará hasta el último cuarto del siglo XIX, cuando los gobiernos de Chile y Argentina

\footnotetext{
* Dr. en Geografía [danielferrer@ezquiaga.es].
} 
animados por el firme propósito de investigar el relieve y la hidrografía de los territorios cordilleranos y precordilleranos en litigio, deciden crear las denominadas Comisiones para los límites. Es en ese momento cuando personajes como Francisco Moreno, Ramón Lista, Carlos Moyano o Juan Tomás Rogers, por citar algunos de los más conocidos, emprenden a instancia de las citadas Comisiones una serie de exploraciones de carácter científico que se distribuyeron entre los años 1877 y 1896. A pesar del avance que estas supusieron, no podremos pensar hasta mucho después en un entendimiento general, o al menos importante, de la configuración geográfica de la Patagonia.

Es precisamente este desfase entre el conocimiento del territorio marítimo y el interior lo que explica que todavía a comienzos del siglo xx existiesen multitud de territorios inexplorados, tanto en el archipiélago de la Tierra de Fuego como en la Patagonia continental. Los sectores más enigmáticos y desconocidos, y también los más inaccesibles, eran, sin lugar a duda, los macizos montañosos y los glaciares del Campo de Hielo Sur.

Tampoco resulta raro que en ese contexto naciese el «andinismo» de la mano de personajes como el alemán Federico Reichert o el italiano Alberto María De Agostini, dignos herederos e importadores de aquel «alpinismo romántico y heroico», como lo denominaba Manuel de Terán ${ }^{1}$, que se desarrolló en Europa en el siglo xIx y que consiguió superar la expresión meramente deportiva al manifestar un interés sensible y culto por la naturaleza, el descubrimiento y la exploración.

Pero la intensa actividad exploratoria realizada por el salesiano Alberto María De Agostini en la Tierra de Fuego y en la Patagonia entre 1912 y 1957 fue mucho más allá de la simple actividad alpinística. Muchas de sus experiencias, adquiridas durante sus casi cincuenta años de viajero incansable, las ha legado con profusión en documentos fotográficos, publicaciones, películas y conferencias, contribuyendo activamente al conocimiento de la «loca geografía» de la región austral.

No se puede despreciar en absoluto el papel que jugó el alpinismo que podríamos considerar «clásico» en el conocimiento geográfico de los territorios montañosos y glaciados de la Patagonia y, de manera específica, en el Macizo del Paine. Aunque hoy pueda resultar un tanto extraño, la diferencia entre el deporte -entendiendo el alpinismo como tal-, la exploración o la ciencia no era tan nítida en aquellos tiempos.

\footnotetext{
${ }^{1}$ Las Formas del relieve terrestre y su lenguaje, discurso pronunciado en 1977 por el profesor Manuel de Terán.
} 
Junto a las contribuciones realizadas por los geógrafos, geólogos, botánicos o ingenieros, que integraban las Comisiones para los Limites, durante el XIX, o por Alberto María de Agostini y otros alpinistas o exploradores, ya en el siglo xx, se deben destacar otras dos aportaciones que tienen también su interés y trascendencia en el proceso de descubrimiento, conocimiento y divulgación de la imagen de la Patagonia interior como espacio geográfico. Se hace referencia al primer viaje turístico realizado en la Patagonia, que tuvo lugar en 1879 y dio lugar en 1880 a la publicación de una importante obra literaria, y a la labor efectuada por el Touring Club de Magallanes, asociación liderada por el alemán, afincado en Punta Arenas, Werner Gromsh, en defensa del turismo regional durante los años 30 del siglo pasado. Precisamente la labor del citado club o asociación, y de los que más tarde recogieron su testigo, resultó decisiva en la campaña de revalorización del territorio Magallánico y, en especial, de la provincia de Última Esperanza, en la que se sitúa el Parque Nacional Torres del Paine.

LAS EXPLORACIONES DE RECONOCIMIENTO GEOGRÁFICO EN LA PATAGONIA INTERIOR (1877-1896)

En el último cuarto del siglo XIX el conocimiento geográfico de la Patagonia interior pasó a ser un objetivo prioritario para los gobiernos de Chile y Argentina, ya que éstos se esforzaban en recopilar la información y los argumentos técnicos necesarios para establecer su soberanía sobre ciertos territorios en litigio. Precisamente, es en este contexto en el que surgen las denominadas Comisiones para los Limites y se comienzan a organizar las primeras expediciones científicas, con el claro propósito de investigar el relieve y la hidrografía de los sectores próximos a la Cordillera, hasta ese momento prácticamente desconocidos.

A partir del año 1877 Argentina se destacó en todas estas campañas y personajes como Francisco Moreno, Ramón Lista o Carlos Moyano, realizaron una encomiable labor, que se prolongó durante años. El país vecino, aunque desde luego desarrolló una actividad mucho más modesta, también contó con profesionales de gran valía como el oficial de la Armada Juan Tomás Rogers o el alemán Hans Steffen.

En muchas de estas expediciones los expertos extranjeros ejercieron un papel fundamental. Por ejemplo el naturalista italiano Clemente Onelli colaboró activamente con Francisco Moreno y recorrió de manera independiente la zona montañosa ubicada entre el actual Parque Nacional Los Glaciares, en Argentina, y el ahora Parque Nacional Torres del Paine, en Chile. 
El alemán Rodolfo Hauthal fue contratado también por la Comisión Argentina como geólogo, siendo el primero en investigar sobre el glaciar que hoy lleva el nombre de «Perito Moreno», al que entonces denominó "Bismark"2, en recuerdo del canciller prusiano. Su afición por el alpinismo le puso en contacto con el químico y escalador alemán Federico Reichert, el verdadero impulsor del alpinismo en la Patagonia.

El gobierno de Chile también contó con la colaboración del ya mencionado Hans Steffen, quien exploró en reiteradas ocasiones la vertiente occidental de la Cordilllera. Sus observaciones se recogieron en una obra titulada «West Patagonien», publicada primero en Chile y después en Berlín en 1919. Durante muchas de estas campañas se efectuaron también interesantes trabajos sobre botánica o consideraciones muy diversas sobre los recursos naturales de cada zona.

Es precisamente el gobierno chileno el que en 1877, en contrapartida a los trabajos emprendidos por Argentina, encomienda a Juan Tomás Rogers, entonces teniente $2^{\circ}$ de la Armada, el reconocimiento de la precordillera oriental $^{3}$. Dos años más tarde Rogers realizará una segunda campaña con el objetivo de completar las observaciones realizadas en 1877, inaugurando así un periodo de exploraciones con carácter exclusivamente científico en los territorios interiores de la provincia de Última Esperanza.

La primera de sus expediciones parte el 11 de noviembre de 1877 desde el seno Skyring y sigue, grosso modo, el siguiente itinerario: desde el seno el grupo ${ }^{4}$ se dirige hacia el oriente alcanzando la Laguna Blanca por el sur, para después bordearla por su flanco derecho y dirigirse hacia el valle del río Gallegos. Tras vadear el río los expedicionarios siguen avanzando en dirección al este hasta encontrar una sierra elevada que Rogers denominó Latorre, en señal de respeto y gratitud hacia un superior de la Armada. Es precisamente en este punto donde el grupo varió su rumbo $180^{\circ}$

\footnotetext{
2 Anteriormente (1879), el oficial de la armada chilena Juan Tomás Rogers lo había denominado "Francisco Gormáz", en deferencia hacia el entonces Director de la Oficina Hidrográfica de la Marina de Chile.

${ }^{3}$ En 1869 George Ch. Musters había realizado una larga travesía entre Punta Arenas y Santa Cruz y en 1877 Francisco Perito Moreno la repitió en sentido contrario ampliando las observaciones efectuadas por el alemán, pero ambos se habían mantenido siempre muy alejados de la cordillera y la precordilllera.

${ }^{4}$ El equipo de trabajo estaba compuesto por el propio J. T. Rogers, el guardiamarina Luis V. Contreras y el joven naturalista Enrique Ibar Sierra, encargado de realizar los trabajos de botánica; todos eran militares y tripulantes de la corbeta "Magallanes". Además contaban con el apoyo indispensable de los baqueanos Zamora y Jara, que actuaban como guías.
} 
para dirigirse hacia el Pacífico, con la intención de alcanzar el seno de Última Esperanza.

De este modo, el 30 de noviembre reconocen el tramo alto del río Turbio y llegan hasta la Sierra de Dorotea, donde las dificultades del terreno les obligan a regresar al campamento de la Sierra Latorre. Desde este punto se dirigen al norte y el día 8 avistan por fin el río Santa Cruz, llegando dos días después hasta su nacimiento, situado en el Lago Argentino. La expedición finalizaría, por causas mayores, el día 15, cuando Rogers y los suyos se encontraban en lo que actualmente es la localidad de Calafate.

La segunda expedición tuvo lugar dos años más tarde y aunque realmente difiere muy poco de la primera en cuanto a su recorrido, si incluye una nueva y decisiva variante: la exploración del distrito lacustre preandino. Como señala acertadamente el profesor Mateo Martinic ${ }^{5}$, desde que a mediados del siglo XIX se estableciesen los primeros chilenos en la población de Punta Arenas, las incursiones hacia el interior de la región habían sido esporádicas y nunca habían tenido, desde luego, ninguna finalidad geográfica.

En efecto, el 28 de febrero de 1879 Rogers penetra en dirección al Paine siguiendo el valle que forma el río Vizcachas y comienza un recorrido que le conducirá hasta los lagos Nordenskjöld, al que denomina Serpiente; Sarmiento, al que bautiza con el nombre de Angosto, y Toro. Su itinerario le permite también divisar una sección del lago Pehoé, aunque Rogers en realidad lo confunde con el propio Lago Sarmiento. En esta ocasión acompañaban a J. T. Rogers el guardiamarina Víctor M. Donoso, el marinero J. D. Albornoz, los baqueanos Zamora ${ }^{6}$ J Jara y un tal Agustín Urbina.

Las observaciones que realizan los miembros de la expedición sobre el drenaje de estos enormes lagos les lleva a establecer la independencia de todo el conjunto fluvio-lacustre del Paine $e^{7}$. Con estas averiguaciones y la información obtenida en la campaña de 1877 Rogers pudo realizar por fin una interpretación general en la que defiende la independencia de las cuencas hidrográficas atlánticas y pacíficas de la Patagonia meridional. Como se po-

\footnotetext{
${ }^{5}$ En Última Esperanza en el tiempo (1985), op. cit. en bibliografía general.

${ }^{6}$ En 1870 Zamora ya había explorado la zona del Paine. Según M. Martinic Santiago Zamora llegó a la ciudad de Punta Arenas en 1868 junto a un grupo de colonos que viajaban bajo la protección del Gobernador Viel. Al no encontrar oportunidades en la población decidió dedicar su vida a las labores del campo, la caza y la exploración, llegando a convertirse con el tiempo en un gran conocedor del territorio interior y en baqueano legendario.

7 Efectivamente todo el sistema fluvio-lacustre del Macizo del Paine es independiente y desagua hacia el Pacífico a través del caudaloso río Serrano y el Seno de Última Esperanza.
} 
drá suponer, este descubrimiento resultará crucial para las futuras demarcaciones.

Aunque los expedicionarios no llegaron a penetrar en el Macizo del Paine, posiblemente intimidados por el impotente caudal del río Paine (al que entonces denominan «Blanco»), si tuvieron la oportunidad de observarlo con detalle. Precisamente las primeras referencias escritas sobre este grupo montañoso salen del puño y letra de Rogers, que se refiere a él en los siguientes términos:

"La Cordillera de los Baguales 8 , que es solamente una parte o sección de los Andes, es de formas muy caprichosas y sus cimas son nevadas. Aparece truncada en su parte meridional, dejando un monte cortado a pique y tres puntas notables, que se divisan en la lontananza y que las gentes de la región llaman Paine por su semejanza con otra montaña del mismo nombre que se halla en la República Argentina».

Con todo el material recopilado por J. Tomás Rogers y por Luis V. Contreras en las dos expediciones, el ingeniero y cartógrafo Alejandro Bertrand realiza lo que se podría considerar la primera «carta particularizada» de la Patagonia oriental, a la que curiosamente denominó «Derrotero de la Espedición a la Patagonia» ${ }^{9}$. Realmente se trata de un mapa muy elemental e impreciso, que muy pronto será superado por los trabajos cartográficos editados por el Instituto Geográfico Argentino (IGA) en 1886 (plano «Gobernación de Santa Cruz» a escala 1.2.000.000) y por el ingeniero Carlos Soza Bruna años más tarde («Carta de la Extremidad Meridional de Sud América», 1890).

El explorador sueco Otto Nordenskjöld presentó en 1897 un trabajo mucho más serio y riguroso (Map of the Magellan Territories) en el que ya se dibujan los principales elementos del relieve (Cordillera de los Andes, Macizo Paine, Sierra Baguales y cerros Dorotea, Castillo y Toro), cursos fluviales (Payne, Baguales, de las Chinas, Guillermo, Tres Pasos y Serrano) y lagos (Toro, Sarmiento, Azul, Dickson y Balmaceda). Pero la verdadera «revolución» de la cartografía se produce gracias a la incansable labor de los especialistas de la Comisión Chilena de Limites, con motivo del laudo de la Corona Británica, que tuvo lugar en 1902.

${ }^{8}$ Los baqueanos habían denominado genéricamente a todos los territorios interiores que quedaban al norte de Punta Arenas como la "región de los baguales" y Rogers adopta esta misma toponimia refiriéndose a la "Cordillera de los Baguales".

9 Resulta curioso que Bertrand lo denominase "derrotero" pues, en rigor, este es un término que se emplea en náutica para denominar el rumbo trazada en una carta de navegación. Posiblemente la condición de marinos de J. Tomás Rogers y Luis V. Contreras pueda explicar este hecho. 


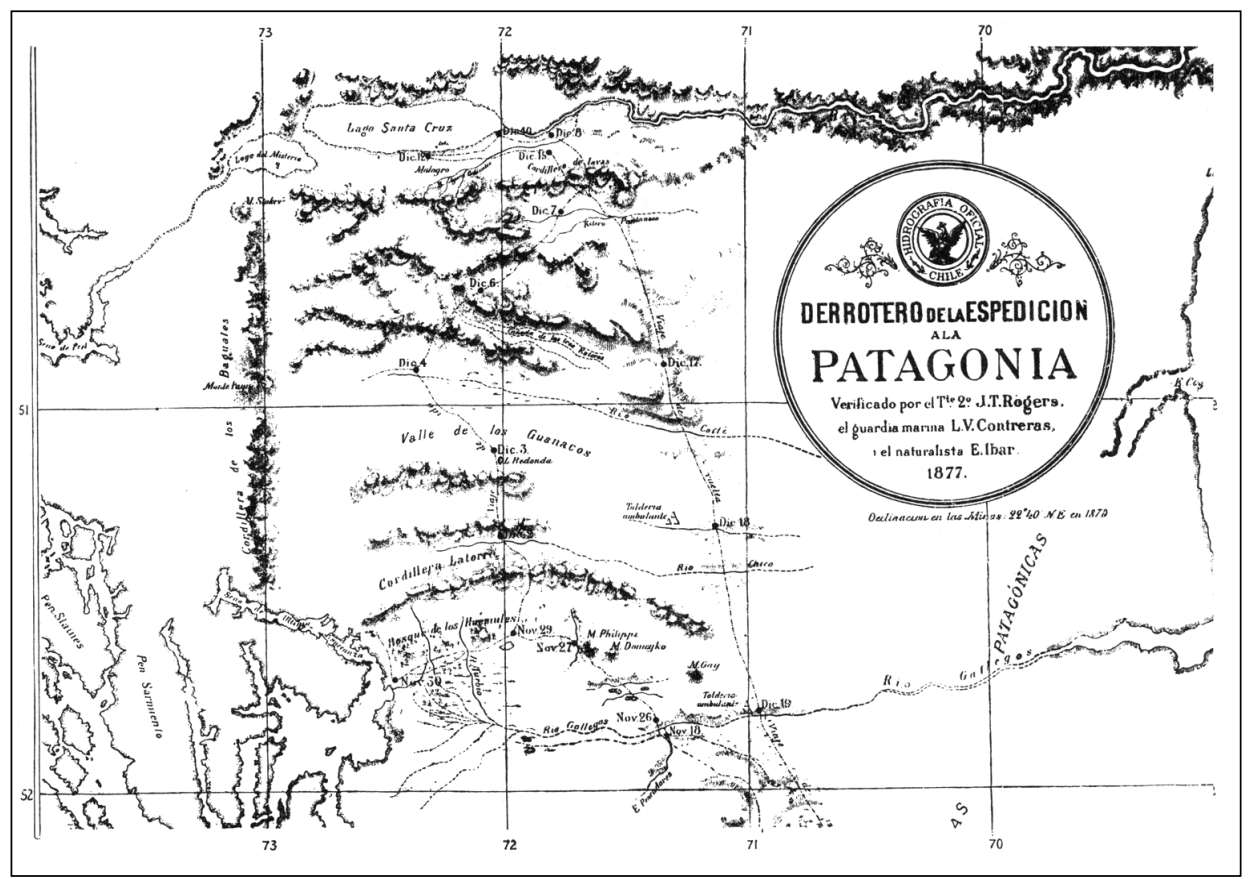

IMAGEN 1. "Derrotero de la Expedición a la Patagonia”, realizada por Alejandro Bertrand

Después de los trabajos realizados por Juan Tomás Rogers muchos otros científicos exploraron la geografía patagónica, pero sólo unos pocos se adentraron hasta el sector del Paine. A finales de siglo, como señala Mateo Martinic $^{10}$, se cierra el ciclo de exploraciones de reconocimiento geográfico, en general, para dar paso a un periodo de estudios más especializados. Este honor le corresponde al famoso explorador antártico Otto Nordenskjöld, que en 1895-96 recorrió diferentes sectores del Macizo Paine realizando una serie de consideraciones geomorfológicas muy interesantes.

En dos décadas el territorio interior de la provincia de Última Esperanza había dejado de ser un gran desconocido gracias, en parte, a la labor de hombres como Juan Tomás Rogers, Serrano, Moyano o el propio Nordenskjöld.

${ }^{10}$ En Última Esperanza en el tiempo (1985), op. cit. en bibliografía general. 
TABLA 1

EXPLORACIONES EN EL ENTORNO DEL MACIZO PAINE (1870-1897)

\begin{tabular}{|c|c|c|c|c|}
\hline Año & Explorador & Nacionalidad & Sector recorrido & Objetivo \\
\hline 1870 & Zamora & Chilena & $\begin{array}{l}\text { Sector entre el río de las Chinas } \\
\text { y el río Baguales con incursión } \\
\text { hacia el norte }\end{array}$ & $\begin{array}{l}\text { Conocimiento } \\
\text { del medio }\end{array}$ \\
\hline 1879 & F. Dixie & Británica & Río de las Chinas y Laguna Azul & $\begin{array}{l}\text { Expedición } \\
\text { recreativa }\end{array}$ \\
\hline 1879 & $\begin{array}{l}\text { J. Tomás } \\
\text { Rogers }\end{array}$ & Chilena & $\begin{array}{l}\text { Lagos Nordenskjöld, Sarmiento, } \\
\text { Pehoé y Toro }\end{array}$ & $\begin{array}{l}\text { Conocimiento } \\
\text { científico }\end{array}$ \\
\hline 1884 & Moyano & Argentina & $\begin{array}{l}\text { Sector entre el río de las Chinas } \\
\text { y el río Baguales con incursión } \\
\text { hacia el norte y Sierra y Lago Toro }\end{array}$ & $\begin{array}{l}\text { Conocimiento } \\
\text { científico }\end{array}$ \\
\hline 1887 & $\begin{array}{l}\text { A. del Castillo } \\
\text { y Greenwood }\end{array}$ & Argentina & Idem que Moyano & $\begin{array}{l}\text { Conocimiento } \\
\text { científico }\end{array}$ \\
\hline $\begin{array}{c}1891 \\
y \\
1892\end{array}$ & R. Lista & Argentina & $\begin{array}{l}\text { Sector entre el río de las Chinas } \\
\text { y el río Baguales con incursión } \\
\text { hacia el norte }\end{array}$ & $\begin{array}{l}\text { Conocimiento } \\
\text { científico }\end{array}$ \\
\hline 1896 & Nordenskjöld & Sueca & Lago Dickson & $\begin{array}{l}\text { Conocimiento } \\
\text { científico }\end{array}$ \\
\hline 1897 & Nordenskjöld & Sueca & Lago Grey y Lago Tindall & $\begin{array}{l}\text { Conocimiento } \\
\text { científico }\end{array}$ \\
\hline
\end{tabular}

El primer viaje turístico a la PATAgonia

En 1879 tuvo lugar un acontecimiento extraordinario para la historia de Magallanes: un grupo de aristócratas ingleses desembarcaba en Punta Arenas para realizar una trepidante aventura por unos territorios prácticamente desconocidos para el hombre blanco, protagonizando lo que se podría considerar el primer viaje turístico a la Patagonia. El carácter pionero de esta iniciativa adquiere una dimensión singular si tenemos en cuenta el hecho de que Florence Dixie, el único integrante femenino de la expedición, narró sus vivencias en un diario que dio objeto un año más tarde a la publicación de la obra Across Patagonia ${ }^{11}$.

\footnotetext{
${ }^{11}$ El libro fue publicado en Londres en el año 1880 por Richard Bentley and Son y reeditado en 1882 en Alemania bajo el título "Bei den Patagonien. Ein Damenritt durch unesforschte 
La expedición estaba formada por cinco miembros, el barón Sir Alexander Beaumont Dixie, su esposa Lady Florence Caroline Douglas, el hermano de ésta, Lord James Douglas, Mr. Julius Beerbohm y un tal Storer, presumiblemente el sirviente. Según M. Martinic ${ }^{12}$, éstos "conformaban un grupo de jóvenes entusiastas -sportmen genuinos- característicos de la época victoriana y como tales, amantes de la caza y los caballos, de la vida al aire libre y de los placeres mundanos a los que eran aficionados los nacidos en noble cuna".

Ninguno, exceptuando a Julius Beerbohm ${ }^{13}$, contaba con experiencia en la Patagonia y, además, su información sobre el territorio era mínima. Hay que considerar que por aquel entonces el interior de la región estaba prácticamente inexplorado, y salvo algún que otro expedicionario ${ }^{14}$ o los llamados "baqueanos"15, que recorrían las zonas salvajes en busca de "baguales" (caballos salvajes) o de caza, nadie se había adentrado en él.

En definitiva, un territorio enigmático, lleno de sorpresas y a tenor de lo que relataban los baqueanos, realmente hermoso ${ }^{16}$. Pero esta realidad, lejos de constituir un obstáculo, supuso para los expedicionarios un aliciente más, como lo demuestran las palabras de Florence Dixie al referirse a la elección de su destino:

"Lo escogí precisamente porque era un lugar exótico y lejano. Hastiada momentáneamente con la civilización y su entorno quería escapar a algún lugar donde pudiera estar lo mas alejada de ella como fuera posible. Sin duda hay regiones salvajes más favorecidas por la naturaleza en muchos aspectos. Pero en ningún otro lugar está uno completamente a solas. En ningún otro lugar hay un Área de 100.000 millas cuadradas sobre las que se pueda galopar y donde junto con gozar de un clima vigorizante se está libre de fiebres, amigos, tribus salvajes, animales dañinos, telegramas, cartas y todas las demás incomodidades a la que uno está expuesto en cualquier otro lugar. A estos atractivos se sumaba el pensamiento siempre tentador y grandioso para una mente activa, de que alli podría penetrar en vastas regiones salvajes, vírgenes aún al paso del hombre [...] Yo iba ser la primera en contemplarlas. Un placer egoista, es verdad..."

Jagdgründe" ("Entre los Patagones. Una amazona a través de inexplorados lugares de caza"). En 1996 la Universidad de Magallanes (UMAG, Chile), consciente de la importancia de esta obra, publica una traducción al castellano.

12 En A través de la Patagonia, op. cit. en bibliografía general.

13 En 1877 había viajado desde la bahía de San Julián, donde quedó bloqueado al perder su barco, hasta Punta Arenas en compañía de unos cazadores de avestruces. Relató sus vivencias en un pequeño libro que tituló Wanderings in Patagonia.

${ }^{14}$ Ninguno había llegado entonces hasta los aledaños del Macizo Paine, J. Tomás Rogers lo haría meses después de que concluyese el viaje de Dixie y su grupo.

${ }^{15}$ El "baqueano" Zamora ya había recorrido la zona del río de las Chinas en 1970.

16 En sus relatos se referían a lugares con "montañas de maravillosos perfiles, bosques enmarañados, espejos lacustres y abundancia de caballos salvajes...”. 
El grupo parte de la población de Punta Arenas en enero de 1879 para completar una ruta a caballo de más de 1.000 kilómetros. En su recorrido atraviesan áridas y desoladas estepas, zonas alomadas, vaguadas, bosques, ríos y lagos hasta por fin culminar su exploración con el descubrimiento del Macizo del Paine. Aunque transportan sus propios víveres, se abastecen principalmente de su propia caza y su dieta se compone básicamente de carne de guanaco, ñandú y caiquén.

Durante las primeras jornadas los protagonistas progresan paralelos a la costa, pero a medida que avanzan los días comienzan a dirigirse hacia el interior (noroeste), perdiendo definitivamente contacto con "la civilización". En este contexto se produce el encuentro entre los ingleses y un grupo de indios nómadas de la Patagonia, momento en que Florence Dixie describe en su obra de manera prolija.

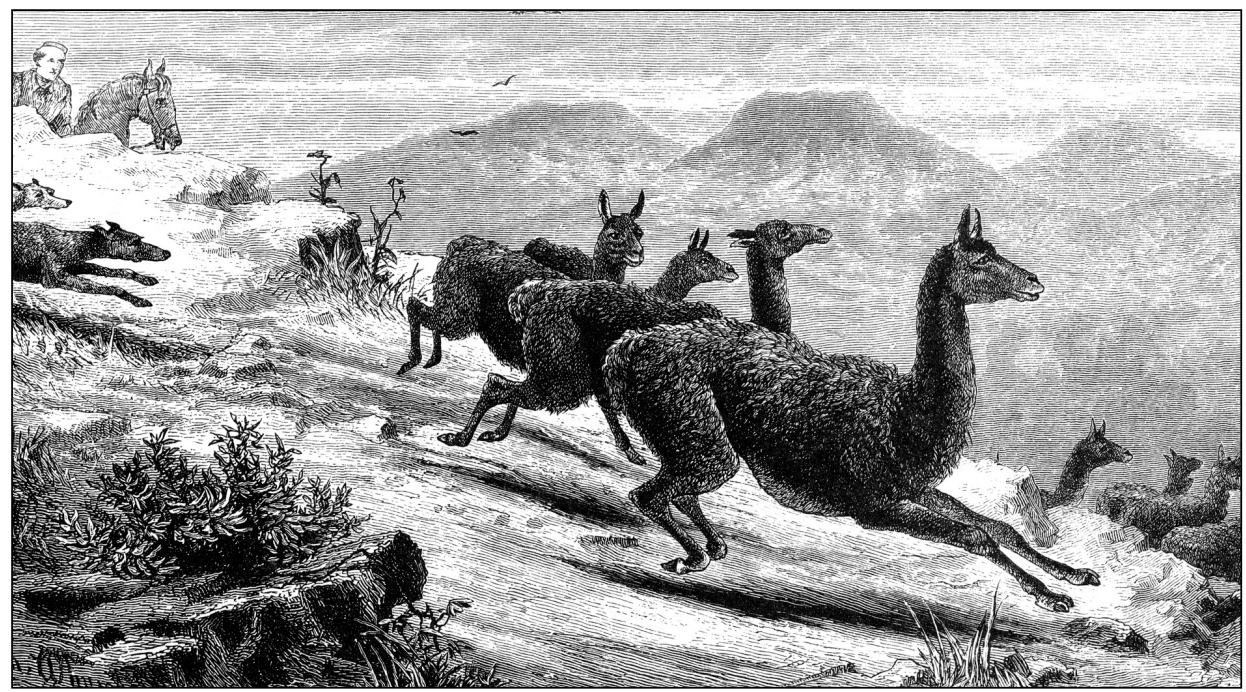

IMAGEN 2. La caza de guanaco, por Julius Beerbohm

Tras abastecerse de carne y entregar en compensación algunos artículos a los indios, los expedicionarios prosiguen camino deseosos de penetrar en un territorio donde abundase la caza. Después de muchos días de cabalgata se produce el primer contacto con el grupo montañoso del Paine, lo que supone una brusca ruptura con los terrenos esteparios recorridos en los días previos. Esta situación maravilla a Florence Dixie, como a sí lo reflejan sus palabras:

Estudios Geográficos, Vol. LXX, 266, pp. 125-154, enero-junio 2009 ISSN: 0014-1496, eISSN: 1988-8546, doi: 10.3989/estgeogr.0456 
"La premura con que este nuevo paisaje había irrumpido en mí intensificaba considerablemente su efecto. Sólo ayer había estado en la llanura con su eterna monotonía de color y contorno, anoche nos habíamos acostado, pensábamos, en un desierto monótono y similar y ahora, como por arte de magia, de las entrañas de la tierra había brotado alrededor de nosotros un imponente y glorioso paisaje. Absolutamente diferente en su diversidad de contorno y color a los que unas horas antes nos había deprimido y fastidiado como es fácil de imaginarse."

A medida que transcurrían los días y el grupo continuaba avanzando en dirección al Macizo Paine, las panorámicas debieron de mejorar considerablemente porque las descripciones de la autora se hacían más profusas y apasionadas. Es precisamente en este pasaje de la obra cuando Dixie alude por primera vez a las Torres del Paine.

"El fondo estaba conformado por cerros boscosos, detrás de los cuales se encumbraba nuevamente la cordillera ${ }^{17}$. Tres altos picos de tinte rojizo y de la misma forma que la aguja de Cleopatra, constituían un aspecto sobresaliente en el paisaje ${ }^{18}$. Los arbustos de calafate eran aquí de un tamaño que nunca antes habíamos visto en las planicies y estaban cubiertos de frutos maduros, sobre los cuales gran número de pajaritos se deleitaban vorazmente [...] La tierra escarpada ondulante que se extendía en dirección a los tres picachos de Cleopatra nos colmó de un impaciente deseo de explorar este territorio desconocido [...]"

Para satisfacer su creciente curiosidad, el grupo continua su incursión hacia las Torres del Paine, superando todos los accidentes del terreno que dificultaban su progresión. Sin duda, la expedición alcanza su punto álgido con el descubrimiento del grupo montañoso y la exploración de su entorno, pero la idea de regresar a la civilización, después de tantos días de sacrificio, comenzó a imponerse en el grupo. Después de unos días más sosegados, emprenden el camino de regreso hacia la ciudad de Punta Arenas.

Lady Florence Dixie escribe justo al final de su novela, al recordar la experiencia vivida en la Patagona:

"Mientras escribo, esos días vuelven vividamente a mi mente otra vez y en mi fantasía contemplo esa distante y desértica tierra, la tierra de las llanuras solitarias donde guanacos, avestruces y los indios andan a la aventura lejos del conocimiento de la humanidad y donde pasé un tiempo despreocupada y feliz, el que nunca podré olvidar. Recuerdo los días en que luego de una larga y cansadora cabalgata dormía con mi

${ }^{17}$ En rigor, la autora identifica erróneamente el Macizo Paine con la Cordillera de los Andes cuando en realidad se trata de un cuerpo intrusivo totalmente independiente de esta última.

${ }^{18} \mathrm{La}$ autora se refiere a las Torres del Paine. 


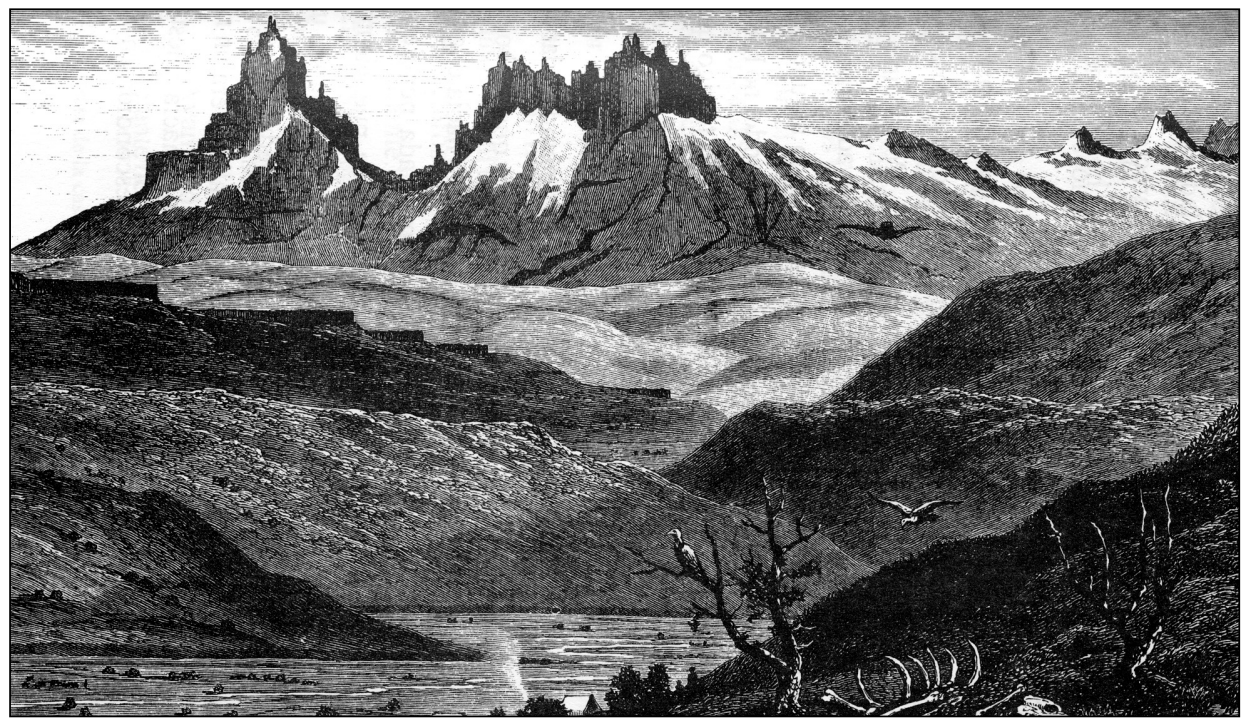

IMAGen 3. La "Cañada de los Baguales", por Julius Beerbohm

montura como almohada, el cielo abierto arriba, el sueño más profundo y dulce que haya jamás dormido antes. Recuerdo esas vistas con grandiosas montañas donde seguimos la huella de los caballos salvajes hasta su guarida, a través de los bosques de hayas encerradas en valles, a través de lagos solitarios, por torrentes de montaña donde ningún mortal había pisado antes. Recuerdo una infinidad de emociones, cacerías y muchas noches agradables alrededor del ameno fuego de campamento.

También recuerdo muchas incomodidades, el terremoto, la lluvia que nos empapaba, el bochornoso sol, los despiadados mosquitos y los terriblemente demoledores vientos. Pero con el placer que miro hacia atrás mi vida silvestre en la Patagonia, poco pueden disminuir estos desagradables recuerdos. Pero en conjunto, contando todo, fue un tiempo feliz y un tiempo que volvería alegremente a pasar [...]".

\section{TOURING CLUB, LOS VISIONARIOS DEL TURISMO}

A mediados del año 1931 un grupo de ciudadanos de Punta Arenas, agrupados en torno a la figura del profesor Werner Gromsh ${ }^{19}$, fundan una aso-

\footnotetext{
19 Se sabe muy poco de la vida de este personaje. El escritor chileno Francisco Coloane se refiere a él en su novela autobiográfica titulada "Los pasos del Hombre" en los siguientes términos:
} 


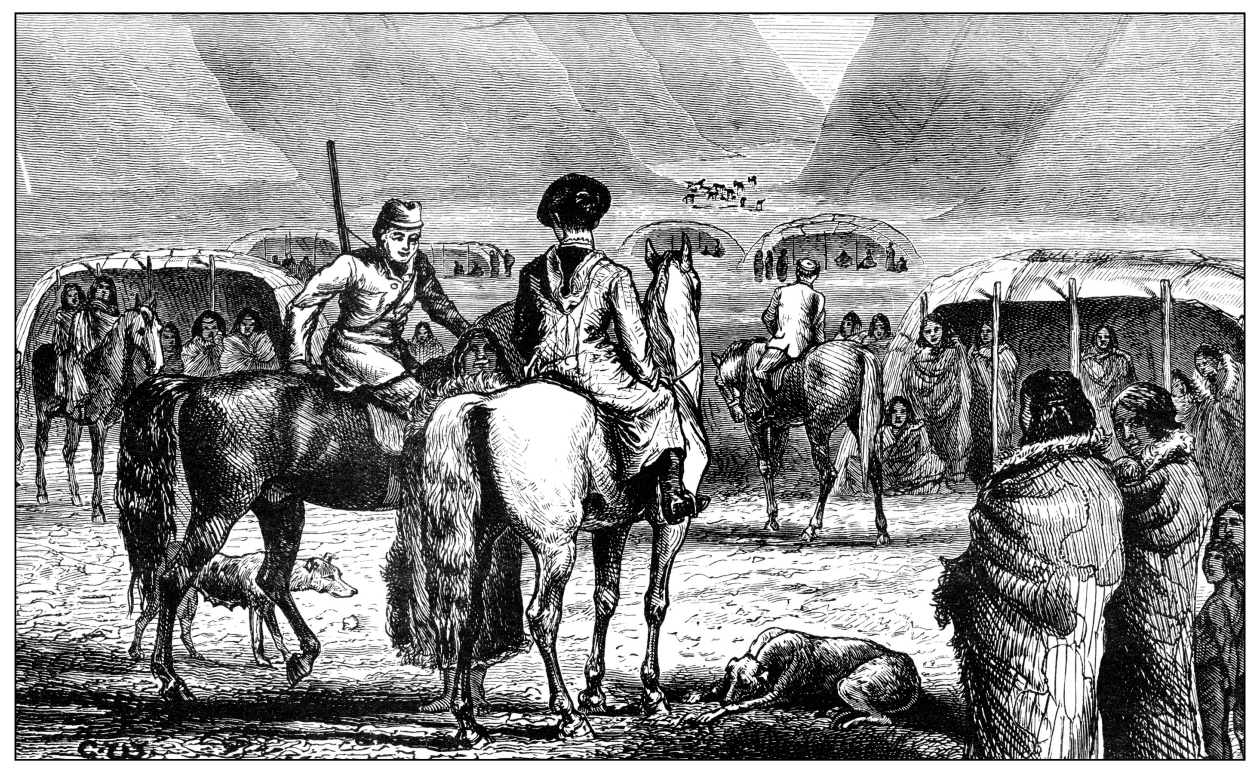

IMAGEN 4. Florence Dixie en un poblado indígena, por Julius Beerbohm

ciación que nace sin ánimo de lucro y con el firme propósito de promover el desarrollo de una industria turística regional sobre la base de la explotación de los recursos naturales del territorio, que ellos consideraban, acertadamente, muy valiosos. Deciden bautizarla con el nombre anglosajón de Touring Club, posiblemente por iniciativa del propio Gromsh.

Aunque a priori pudiera parecer un objetivo un tanto ambicioso para los tiempos que corrían (realmente no se daban los condicionantes necesarios para acometer un proyecto de esta envergadura), lo cierto es que todos los miembros del Touring Club eran perfectamente conscientes de los numerosos obstáculos a los que se enfrentaban y, lejos de desanimarse, dirigieron sus esfuerzos a conseguir del Gobierno central un apoyo que consideraban indispensable.

\footnotetext{
"No puedo olvidar sus clases de inglés en las que a veces se apartaba de la materia para contarnos episodios de su existencia vagabunda. Siendo alemán, había aprendido inglés en China y, quien sabe por que caprichos del destino, vino a enseñar este idioma en el más lejano rincón de Chile. Don Werner nos llevaba en excursiones por los campos. No aprendí con él mucho inglés, pero sí bastante de la vida".
} 
Entre sus peticiones destacaban, entre otras, la creación de una pequeña red de «Parques Nacionales» 20 sobre terrenos fiscales, la construcción de una serie de infraestructuras de apoyo a la actividad (carreteras y hoteles básicamente) o la implementación de una «Ley de Impuestos al Turismo», encaminada a conseguir un cierto grado de autonomía regional en materia económica (al parecer el Gobierno central recaudaba en Magallanes en 1935 algo más de 200.000 pesos chilenos en concepto de impuestos pero no reinvertía ni un solo céntimo para fomentar el turismo). También solicitaron ayudas y exenciones fiscales destinadas a fomentar la inversión de los empresarios o subvenciones para proyectos turísticos de interés general, todas propuestas muy "avanzadas" para la época.

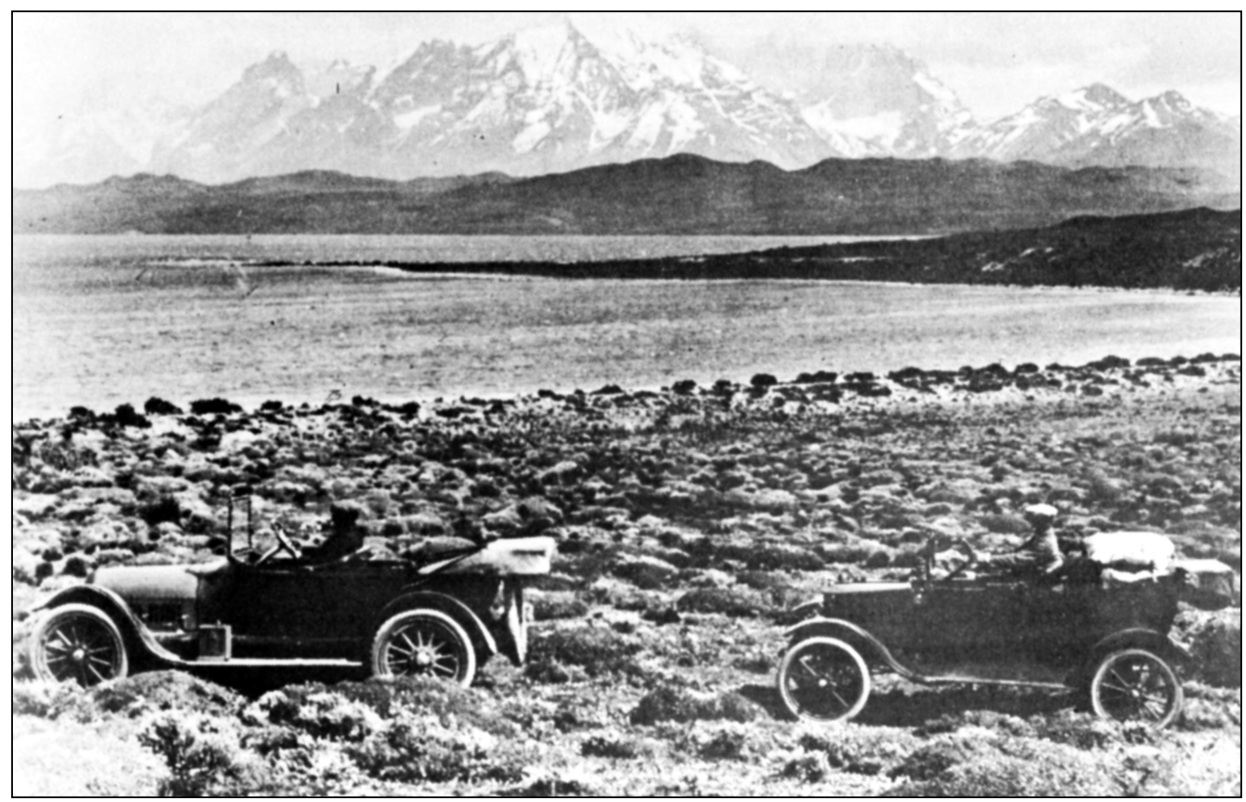

Imagen 5. Turistas en automóvil visitan el Parque Nacional Torres del Paine a finales de los años 20

20 Por Parque Nacional entendían una porción del territorio acotado para el uso exclusivamente turístico careciendo, por lo tanto, de las connotaciones que posee en la actualidad una figura de protección de este tipo. En ocasiones hablaron indistintamente de "Parques Nacionales de Turismo". 
Pero lo cierto es que todas sus campañas, si se valoran los éxitos alcanzados, resultaron decepcionantes, ya que las reivindicaciones de estos entusiastas siempre chocaron con el desinterés de un gobierno excesivamente centralista y más preocupado en asuntos de otra índole.

Hubo que esperar hasta los años 50 para que su labor fuera retomada con éxito por una serie de instituciones regionales, entre las que figuraban el propio Touring Club, el Centro Patagónico de Historia Natural, el Club Andino de Magallanes y el Foto-Cine Club, todas con sede en Punta Arenas.

No obstante, aún asumiendo que fueron más los éxitos que los fracasos, no se debe pasar por alto la labor que estos intelectuales y activistas desarrollaron, en lo que se refiere al conocimiento del territorio regional. Así, desde que se creó el Touring Club, algunos de sus socios más activos se esforzaron por obtener un conocimiento más amplio de los recursos naturales que pretendían promocionar y a tal efecto realizaron múltiples mini-expediciones, tanto marítimas como terrestres, aprovechando las vacaciones de verano o simplemente alguna festividad.

Como era de esperar, enseguida dirigieron sus esfuerzos hacia la provincia de Última Esperanza, territorio que a su juicio «estaba llamado a ser en un futuro cercano, la región de mayor importancia para el desarrollo del turismo austral». Dentro del ámbito provincial, el Paine (o «la región del Paine» como ellos la denominaban) se convirtió desde muy pronto en el centro de interés principal.

Las investigaciones en hemeroteca ${ }^{21}$, indican que ya en 1932 el Touring Club defendía públicamente -y con gran tesón- su proyecto de crear el Parque Nacional de Turismo de Magallanes. Estaba previsto realizar un hotel y ofrecer una serie de excursiones y actividades por los alrededores. De haberse concretado esta pretensión, el hipotético Parque habría estado situado, precisamente, en el sector del Paine, sin que se conozca con precisión sus límites, lo que sin duda demuestra que los miembros del Touring Club conocían perfectamente cuales eran los recursos más valiosos de su región.

En plena campaña de concienciación, el propio Gromsch relata, en un artículo que intencionadamente titula «A través del Parque Nacional de Turismo de Magallanes»22, la excursión estival realizada junto a sus compañeros Hartmuth y Hornburg al glaciar Dickson en 1932, años en los que los pioneros del

${ }^{21}$ En el curso de la investigación se consultaron en la hemeroteca del Instituto de la Patagonia, en la ciudad de Punta Arenas (Chile), varios de los textos publicados en la prensa regional entre 1932 y 1935 y firmados por el Touring Club y Werner Gromsch.

22 Posiblemente el título del artículo guardaba relación con el de "Across Patagonia". Se publicó en "El Magallanes", edición dominical del 27 de Marzo de 1932. 
alpinismo comenzaban a llegar al Paine. Este relato, y algunos otros aparecidos en la prensa de la época, constituyen un ejemplo de la intensa labor de divulgación ejercida por el Touring Club de Magallanes durante los años 30, dentro de lo que se debería considerar su «campaña integral» de promoción de los atractivos de la región.

En los años 50, como ya se adelantaba, una serie de personalidades vinculadas a diferentes instituciones con sede en Punta Arenas, recogen el testigo de Gromsch y los suyos y consiguen lo que se podría considerar el primer éxito en materia de conservación del territorio regional para su uso recreativo. En efecto, en mayo de 1959 se crea el Parque Nacional de Turismo Lago Grey, que cuenta con una extensión aproximada de 4.332 ha y debe ser considerado como el germen del actual Parque Nacional Torres del Paine. Esta es, quizás, la mejor recompensa a su labor.

Realmente nunca sabremos que hubiera pasado si las voces de estos adelantados de su época hubiesen sido escuchadas. Quizás, hoy la XII región podría presumir de contar con una larga tradición en gestión turística o tal vez sus recursos naturales estarían mermados o irreversiblemente dañados, pero lo cierto es que pasaron muchas décadas hasta que las autoridades y la población de Magallanes empezaron a comprender la indiscutible vocación turística de la región, algo que hoy ya nadie parece discutir.

Para terminar, se debe insistir en el carácter visionario de Werner Gromsch y de los otros miembros del Touring Club y destacar su notable aportación al conocimiento del territorio magallánico y de la zona del Paine, en particular, en una época temprana.

\section{Alberto María de Agostini: Un piamontés en el límite del mundo}

La aportación del salesiano De Agostini al conocimiento culto de la Patagonia interior resulta absolutamente fundamental, como ya se adelantaba en las páginas iniciales de este artículo, tanto por el alcance de sus propias exploraciones y campañas como por el amplio legado que nos ofrece ${ }^{23}$.

El contacto del piamontés con la zona austral de América tuvo lugar en 1910 cuando sus superiores, que conocían y apreciaban el espíritu de aventura y sacrificio del piamontés, deciden enviarle al sur de Chile, donde ya fun-

${ }^{23}$ Más de veinte publicaciones e infinidad de artículos, ensayos y columnas de prensa avalan la trayectoria del salesiano como escritor, producción que se complementa con el abundante material gráfico que éste genera. 
cionaban desde hacia unos 20 ó 30 años una serie de misiones de la orden, fundadas por el Monseñor Fagnano. Para llevar a cabo la costosa empresa, éste se había procurado previamente el apoyo de las dos familias más pudientes de la ciudad de Punta Arenas, la Menéndez y la Braun, a las que además implicó en su cruzada personal en defensa del indígena. Como lo hicieron Fagnano y otros compañeros salesianos, el padre De Agostini se posicionó, desde un primer momento, en favor de los indios aborígenes de la Patagonia, intentando por todos los medios, pero sin éxito, frenar el proceso de aculturación y exterminio al que éstos estaban siendo sometidos.

Giuseppe Garimoldi, en el breve ensayo titulado «De Agostini, un piamontés en el extremo sur americano» ${ }^{24}$, describe de manera realista y dura la realidad que se encontró el religioso al desembarcar en estos territorios:

"Cuando en 1910 Alberto María De Agostini atraca en el estrecho, la tragedia de los indios, en parte, ya se había realizado y, rastreados como animales salvajes, estaban perdiendo el orgullo de su propia identidad. Sobre la orilla patagónica del estrecho de Magallanes creció una ciudad que lleva el nombre del gran navegante: Magallanes ${ }^{25}$. Poblada y en crecimiento, la ciudad posee un puerto que registra un pasaje mensual de noventa naves de y para Europa, desde y para las escalas que se asoman al Océano Pacífico. Una zona urbana, con casas, edificios y un teatro para la ópera lírica inaugurado en julio de 1899. Una ciudad, que en el tejido local, es la astilla de un mundo extranjero injertada en una tierra de la cual tiene sólo algunas nociones geográficas incompletas y que se presenta a las poblaciones originarias con la cara de la ignorancia y la brutalidad, despreciando su cultura principal crecida en sintonía con la avara naturaleza de esta tierra".

Efectivamente, el padre De Agostini entró en contacto con un mundo muy dinámico, presidido por los conflictos propios de una sociedad en proceso de construcción. A pesar de todo, el salesiano comenzó desde un primer momento una frenética actividad, realmente difícil de rastrear, que se prolongará durante casi 50 años y en la que consigue compaginar, como bien apuntaba Marco Bongiovanni ${ }^{26}$, "fe y ciencia, misión y cultura". Su gran vitalidad le mantiene vinculado al mundo de la exploración y el montañismo hasta prácticamente el día de su muerte, que tuvo lugar el año 1960 en Torino, la ciudad que le vio ordenarse sacerdote.

Desde su llegada a la región, De Agostini manifestó un notable interés por el archipiélago de la Tierra de Fuego, realizando entre los años 1910 y 1912

\footnotetext{
24 Op. cit. en bibliografía general.

25 Actualmente Punta Arenas, la capital de la XII Región de Chile.

26 Alberto De Agostini, un uomo su due coordinate, op. cit. en bibliografía general.
} 
varias exploraciones indagatorias con el propósito de recopilar información para futuras empresas. En enero de 1913 organiza su primera gran expedición con el objetivo de escalar el Monte Sarmiento (también conocido como Monte Darwin) en compañía de los guías alpinos Abele y Agostino Pession y el naturalista G. B. De Gasperi.

La contemplación de esta colosal montaña provocó en el salesiano una admiración que no dudó en confesar años después:

"Es algo que no se puede olvidar. Cuando, algunos años después de estos viajes míos, tuve ocasión de ver de cerca el Monte Aconcagua, de 7.000 metros de altura, esa visión no causó en mí ni siquiera un pálido reflejo de esa fuerte emoción que sentí cuando me hallé frente a la imponente pirámide del Sarmiento".

Pero los rigores climáticos frustran las ambiciones de los alpinistas, que tras sucesivos contratiempos deciden abandonar su objetivo para dirigirse hacia la zona del Glaciar Marinelli, donde realizan interesantes reconocimientos. La exploración concluye con la ascensión del Monte Olivia, en Ushuaia.

Pero el salesiano no renuncia a escalar esta hermosa montaña y organiza una nueva expedición para diciembre de ese mismo año. En esta ocasión busca la compañía de dos guías del Valle del Sesia. Desde aquel nuevo fracaso del salesiano y su equipo pasaría mucho tiempo hasta que en 1955, cuando ya contaba con más de 70 años, su tesón fuese recompensado y la potente expedición que él apadrinaba consiguiese coronar la cumbre el 7 de marzo.

En el año 1914 De Agostini continúa reconociendo la Cordillera Darwin, donde realiza un intento sin éxito al Monte Italia y escala el Pico Francés y el Monte Belvedere. En la Sierra Alvear, situada junto al Lago Fagnano, asciende al Monte Corbajal. Recorre la península Brecknock, la Bahía Desolada, la isla O’Brien y los canales Beagle y Cockburn. En 1915 explora el sector del Cabo de Hornos, tan temido por los marineros, desembarcando en varias de sus islas.

Es a partir de 1916 cuando el salesiano dirige su atención hacia el continente, inaugurando así un dilatado y fructífero periodo de viajes y exploraciones a través de la Patagonia, un vasto territorio que escondía por entonces muchos secretos, todavía sin desvelar. Según M. Martinic (op. cit.) resulta determinante, en este sentido, la orden que De Agostini recibe de sus superiores eclesiásticos para acudir como sacerdote a la provincia de Última Esperanza, pues es de este modo como el ilustre salesiano entra en contacto con las bellezas naturales de este territorio.

La Provincia de Última Esperanza desborda desde un primer momento las expectativas del salesiano, que no tardará en relatar "las excelencias" de sus paisajes. Después de un reconocimiento bastante exhaustivo de la zona marí- 
tima se adentra hacia el interior y visita durante el verano de 1917 el sector del Paine, al que volvería años más tarde. En 1929 una expedición geográfica a las órdenes del salesiano recorre el frente del enorme glaciar que se desparrama sobre el Seno Eyre, al que bautizan con el nombre de "Glaciar Pio XI", en recuerdo del Papa alpinista.

Un año más tarde De Agostini realiza una exploración desde el Lago Argentino hasta el Monte Torino, salvando un desnivel muy importante y completando lo que prácticamente se podría considerar una travesía integral de la Cordillera patagónica. Le acompañaban, en esta ocasión, dos guías de Courmayeur y el geólogo Egidio Feruglio.

En 1931 recorre el Lago Viedma, el glaciar Upsala y el impresionante Macizo del Fitz Roy, donde realiza la ascensión del Monte Eléctrico $(2.182 \mathrm{~m}$ ). Años más tarde, concretamente en la temporada 1935-36, regresará al Fitz Roy con el auspicio de la Real Academia de Italia y con el compromiso de realizar un inventario detallado de los glaciares del sector y un reconocimiento de los sistemas montañosos que se ubican al oeste.

El interés del salesiano a partir del año 1937 se centra en la región de San Martín, situada más al norte del Macizo del Fitz Roy. Siguiendo su proceder habitual, De Agostini se apresura a coronar la cumbre de alguna montaña para obtener una visión de conjunto del sector. En esta ocasión asciende el Monte Milanesio, divisando los glaciares del Cerro O’Higgins, que descienden hasta el lago homónimo.

Ese mismo año (1937) regresa al Paine para realizar con el piloto Franco Bianco un vuelo sobre la Cordillera. Esta nueva y vertiginosa experiencia, no exenta de riesgo si tenemos en cuenta las turbulencias de la zona y la consistencia del aeroplano, le permitió a De Agostini obtener unas interesantes fotos aéreas del Macizo y sus glaciares. Anteriormente otros pioneros de la aviación habían realizado vuelos en la región ${ }^{27}$, destacando por su carácter exploratorio los efectuados en los años 1928-1929 por el alemán Günther Plüschow a bordo de su hidroavión "Cóndor de Plata".

Entre 1937 y 1943 De Agostini lidera hasta cuatro expediciones al Monte San Lorenzo, su último gran reto personal, consiguiendo la cima en el último intento en compañía de los guías del Club Alpino de Bariloche, Alessandro Hemmi y Heriberto Schmoll.

27 El francés Omar Page había sobrevolado en 1914 la ciudad de Punta Arenas y el Cabo de Hornos. En 1916 los chilenos Fuentes y Castro realizaron la primera travesía aérea del Estrecho de Magallanes y en 1921 se realizaba el primer vuelo postal de la América Austral, entre Punta Arenas y Ushuaia. 
En 1957 De Agostini afronta su última gran empresa, la organización de la expedición al Paine Grande que subvenciona el aristócrata italiano Guido Monzino. Aunque el salesiano ya cuenta con más de setenta años y no participa activamente, desarrolla un papel decisivo al actuar como mediador entre los alpinistas y el gobierno chileno, del que obtiene la exclusividad para intentar escalar la montaña, maniobra que, por cierto, levantó en su día una gran polémica.

Todos estos viajes y exploraciones, y otras muchos, supusieron la base de los trabajos geográficos del salesiano De Agostini. Su primer gran libro estuvo dedicado a la Tierra de Fuego y se publicó en su lengua materna el año 1924 bajo el título "I miei viaggi nella Terra del Fuoco", aunque tras su éxito fue traducido inmediatamente al alemán. Sin embargo, la edición española no salió a la luz hasta 1927.

En 1941 De Agostini edita lo que podríamos considerar su obra de madurez bajo el título "Andes Patagónicos"28. Se trata de una magnífica recopilación de la información adquirida durante sus exploraciones continentales en la que el autor alterna un estilo novelado, con relatos sobre sus vivencias en primera persona, con uno más "académico" y propio de los viejos manuales de geografía. Algunas de sus descripciones, como las que realiza del grupo montañoso del Paine, al que dedica un capítulo completo, deben considerarse hoy como clásicas.

"El Macizo del Paine es, sin rival, el más soberbio y característico grupo de picos y cumbres que posee la Cordillera patagónica austral. Casi aislado de la Cordillera, avanza entre las estribaciones orientales de los Andes como una formidable fortaleza almenada de torres, de pináculos, de cuernos monstruosos audazmente dirigidos hacia el cielo. Por sus colores y su forma es sin duda uno de los conjuntos arquitectónicos más fantásticos y espectaculares que la imaginación pudiera concebir".

El autor aprovecha la publicación para intentar crear una "conciencia" sobre la necesidad de explotar los recursos turísticos de este territorio (es posible que De Agostini conociese personalmente alguna de las publicaciones que vinieron realizando desde los años 30 algunos de los miembros del Touring Club). En un pasaje del citado libro, De Agostini escribe, refiriéndose a la estancia "Río Paine":

"Sería este el lugar ideal para establecer un centro turístico de irradiación con hoteles y medios de transporte, para excursiones a los lagos y a los montes que lo hacen corona".

${ }^{28}$ En 1944 se entrega la segunda edición y en 1949 se publica en italiano. 
En todo caso, hay que señalar que se denota en el salesiano un interés creciente por acercar al público las maravillas del sur de Chile, lo que termina por animarle a publicar en 1946 la primera guía turística conocida sobre la XII región, que titula "Guía Turística de Magallanes y Canales Fueguinos". Sin duda, esta edición supuso todo un hito en lo que se refiere a la incipiente organización de una "industria turística regional". Se trata de una publicación de pequeño formato, que se estructura en once capítulos y que cuenta con abundante material gráfico (mapas, ilustraciones y fotografías). En ella se abordan temas tan variopintos como el descubrimiento del Estrecho de Magallanes, el patrimonio arquitectónico de los salesianos o la fauna y los bosques regionales.

Por fin, en 1955 y 1958 se publican, respectivamente, "Trent'anni nella Terra de Fuoco" y "Sfingi di ghiaccio", las dos obras más completas de Alberto María de Agostini, junto con la ya mencionada "Andes patagónicos".

Como señala Giuseppe Garimoldi, los cronistas de este personaje nunca han destacado la enorme importancia documental que tiene la fotografía del salesiano dentro del contexto general de su obra y sólo algunos autores, como Angelo Schwarz en sus ensayos, han roto una lanza a favor de esta faceta tan injustamente olvidada. La realidad es que su obra escrita quedaría incompleta sin la fuerza que trasmiten sus imágenes, en las que "conviven" una innegable sensibilidad hacia el paisaje y un claro interés por captar el matiz geográfico de las escenas que retrata.

Paradójicamente, durante su vida sí que obtuvo el reconocimiento del público y de los críticos allí donde expuso sus fotografías, siendo incluso laureado en varias ocasiones. Su aparición pública más antigua tuvo lugar en 1907, cuando todavía residía en Italia, concretamente en una exposición organizada por la Sociedad Fotográfica de Florencia. En 1913 se presentan en Santiago de Chile algunas de sus fotos y en 1918 una nueva muestra de más de 110 fotografías, esta vez referida específicamente a la geografía y naturaleza de Magallanes, es presentada en la capital, concretamente en los salones del diario "El Mercurio". Las fotografías recorren varias de las ciudades del país (la exposición fue repetida dos años más tarde en Punta Arenas). Ese mismo año obtiene una medalla de oro en una exposición celebrada en Río de Janeiro. Publica a lo largo de su vida varios álbumes fotográficos e ilustra habitualmente sus publicaciones con el material gráfico que el mismo genera. Se deben recordar también sus dos filmaciones tituladas "Tierras Magallánicas" y "Tierra del Fuego", que fueron difundidas con éxito tanto en América como en Europa. 

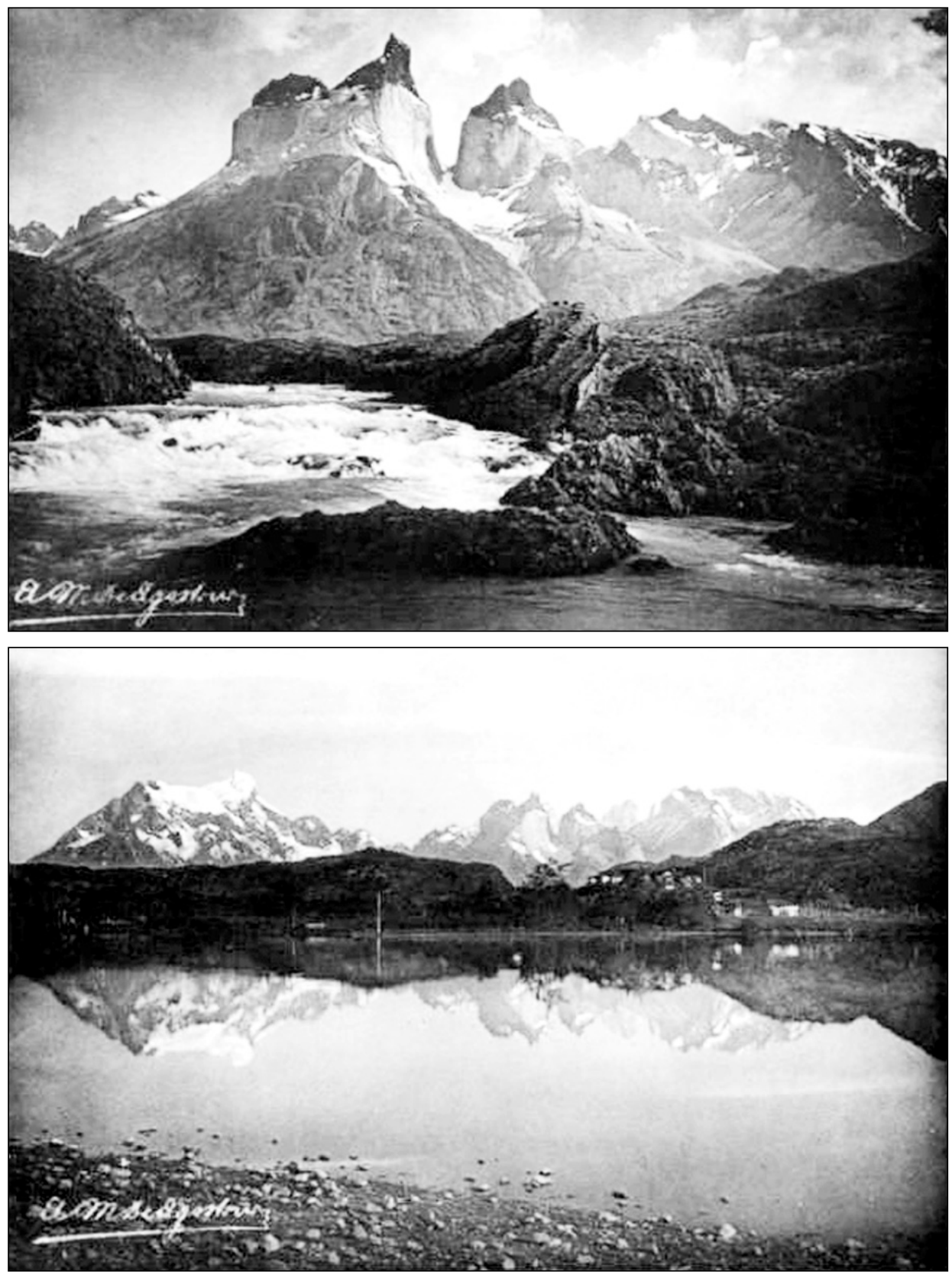

Figura 6. Fotografías del Paine firmadas por Alberto Maria De Agostini

Estudios Geográficos, Vol. LXX, 266, pp. 125-154, enero-junio 2009

ISSN: 0014-1496, eISSN: 1988-8546, doi: 10.3989/estgeogr.0456 
LAS EXPEDICIONES ALPINAS EN EL MACizO PAine (1937-1981)

Las primeras referencias sobre las exploraciones realizadas por los alpinistas en este grupo montañoso las encontramos en los escritos del salesiano A. M. De Agostini y aluden a la actividad realizada por el doctor Gustavo Fester y otros súbditos alemanes, todos miembros del Club Alpino de Bavaria, durante los años 1931 y 1937.

Es precisamente en este último año cuando la cordada formada por Hans Teufel y Stefan Zuck logra ascender a la cima occidental del Paine Chico (2.668 $\mathrm{m})$, a la que denominaran Almirante Nieto, conquistando de este modo la primera de las grandes cumbres de ese grupo montañoso. Aunque la ruta que siguieron no era demasiado técnica (arista N-NE), los escaladores si que tuvieron que progresar, con la ayuda de unos equipos de alpinismo muy rudimentarios, por un terreno mixto de nieve y roca bastante expuesto.

Parece ser que en ese mismo año (1937) se produjo el primer intento de ascensión a la Torre Central, a cargo de dos alpinistas llamados Fester y Jacob, aunque las dificultades de esta escalada enseguida frustraron las ilusiones de la cordada. Algunos años antes de todas estas expediciones miembros del Touring Club de Punta Arenas, liderados por el profesor Werner Gromsch, ya habían realizado pequeñas travesías de reconocimientos en el glaciar Dickson.

El propio W. Gromsch relata su experiencia en el Dickson en un artículo publicado en 1932 en el diario "El Magallanes":

"El único acceso al ventisquero pasa por una parte rocosa y escarpada. El hielo está sucio en el borde debido a la acción del viento que arrastra nubes de tierra sobre él cuando con su indómita fuerza sopla desde el occidente. Por fin encontramos una pasada. Nuestros zapatos, especialmente provistos de ganchos y clavos de acero, nos facilitan el acceso. Por las dudas nos amarramos enseguida a la soga y progresamos lentamente (...). Allí lejos, en el centro del ventisquero, hay un hermoso y alto castillo con una gruta azul en su fondo. Duro y penoso es el camino, pero tras ardua labor logramos escalar los blancos pináculos".

Parece que desde los años 40 hasta comienzos de los 50 la actividad alpinística se detiene -tal vez por la $2^{a}$ Guerra Mundial y los complicados años de postguerra-, pero de nuevo en 1953 comienzan a llegar escaladores al Paine. Algunos miembros del Club Alpino de Bariloche (Argentina) lo hacen con la intención de escalar la montaña más alta, difícil y peligrosa de todo el sector: el Paine Grande (3.050 m).

Son precisamente miembros de este club los que consiguen la primera repetición del Almirante Nieto o la escalada del Cuerno Principal (2.600 m.) 
hasta muy cerca de su cumbre. Peor suerte correrían en el intento a la cima central del Paine Grande ( $2.730 \mathrm{~m}$.), pues pierden a dos de sus componentes en una avalancha de hielo y roca, concretamente a Toncek Pangerc, y al jefe de expedición, Herbert Schmoll. Un año más tarde, durante el verano de 1955, se produce el primer intento chileno a la cumbre principal del Paine Grande, a cargo de L. Kranl, S. Kunstermann, E. Payá y R. Vivanco, pero tan sólo consiguen ascender a la cumbre central y a la cumbre sur $(2.600 \mathrm{~m})$.

En el verano de 1957 llega al Macizo una importante expedición italiana subvencionada por el aristócrata Guido Monzino y apadrinada por Alberto Maria De Agostini, ya por aquel entonces veterano e ilustre aventurero de la América austral, con el firme propósito de ascender hasta los 3.050 metros del Paine Grande. El equipo lo componían 16 miembros, entre los que figuraban algunos de los escaladores más fuertes del momento, entre los que figuraban guías del Valle de Aosta y Valtournanche famosos por sus ascensiones en los Alpes, un fotógrafo, cuatro militares y un médico. Además, la expedición contaba con los mejores equipos y vestimentas para alpinismo que existían por aquellos años.

La conquista de esta codiciada cumbre (27 de diciembre de 1957) se debe considerar como uno de los grandes logros del alpinismo clásico en la Patagonia y solamente es comparable con hazañas como la escalada de la Torre Central, también en el Macizo Paine, o la ascensión al Fitz Roy y al Cerro Torre, en Argentina.

La expedición de Guido Monzino no se relajó tras el éxito conseguido y dirigió sus expectativas, en los primeros días del nuevo año, hacia la más meridional de las tres torres de granito, la Torre Sur $(2.850 \mathrm{~m})$, pero muy pronto descartan la posibilidad de intentar su escalada impresionados por su imponente arista nordeste y se marcan como objetivo la ascensión de la Torre Norte $(2.600 \mathrm{~m}), 250$ metros más baja y sobre todo mucho más asequible desde su cresta sur. Esta cumbre fue un magnífico colofón a la gesta realizada días antes en el Paine Grande y también la última gran ascensión de los años 50 en el Macizo.

Los años 60 serán especialmente fructíferos desde el punto de vista de las "primeras ascensiones", ya que durante la década se resolverán dos de los grandes "retos alpinísticos", por entonces todavía pendientes: la ascensión de la torre central y de la cima sur, en el grupo de las tres Torres del Paine.

El primero de los éxitos fue logrado el día 16 de diciembre de 1963, tras varias semanas de actividad, por una expedición británica liderada por Barrie Page, que contaba entre sus componentes con Christian Bonington y Donald Whillans, afamados alpinistas. La noticia de la conquista de la Torre Central por los británicos tuvo una gran repercusión en los ambientes deportivos y alpinísticos de Europa y fue tratada con amplitud por las publicaciones especializadas. 


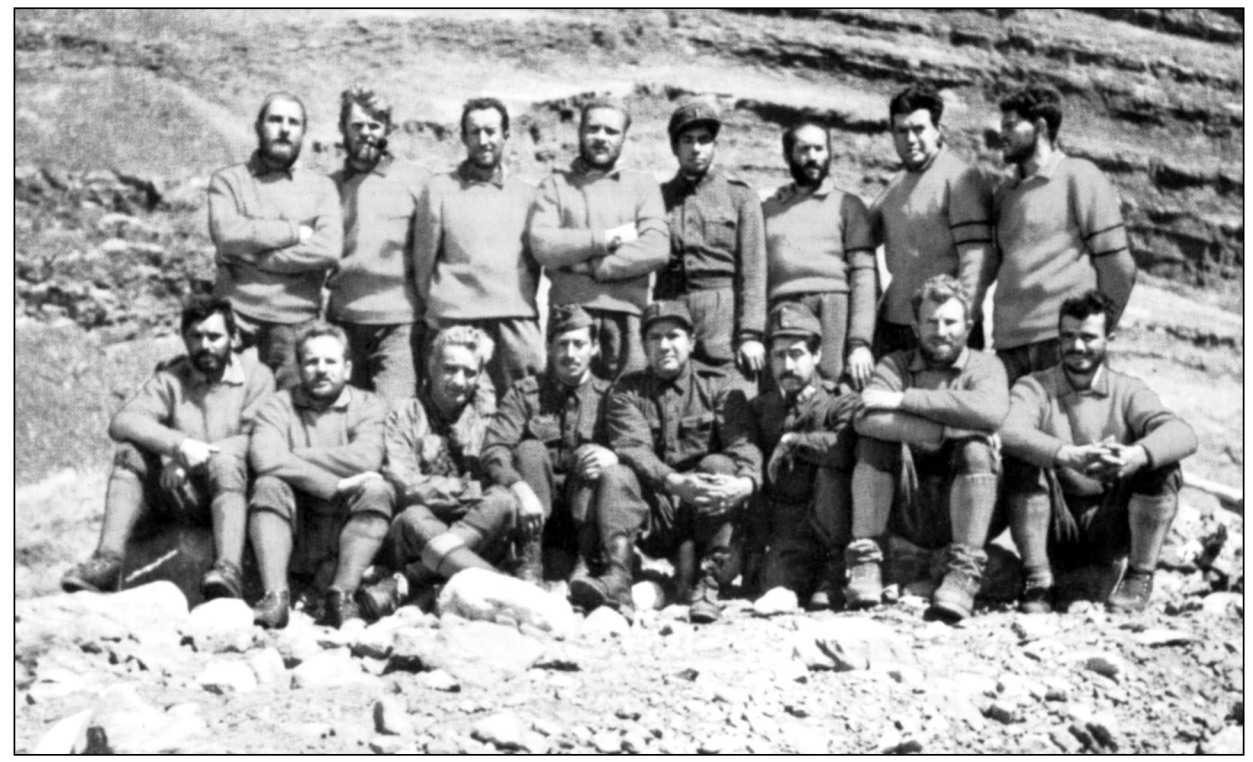

IMAGEN 7. La expedición de Guido Monzino (arriba, cuarto por la izquierda), al completo

El segundo de los retos fue conseguido por la expedición italiana organizada por la sección de Monza del Club Alpino Italiano (CAI), que estaba liderada por Giancarlo Frigeri. Esta expedición reunía un grupo de expertos escaladores en roca ya consagrados por sus rutas en los Alpes y Dolomitas, entre los que figuraban Vasco Taldo, Armando Aeste o Nando Nusdeo. Una racha de buen tiempo permite a los italianos izar su bandera en la cima el día 9 de febrero del año 1964. La

IMAGEN 8. Portada del folleto conmemorativo de la Expedición Británica al Paine

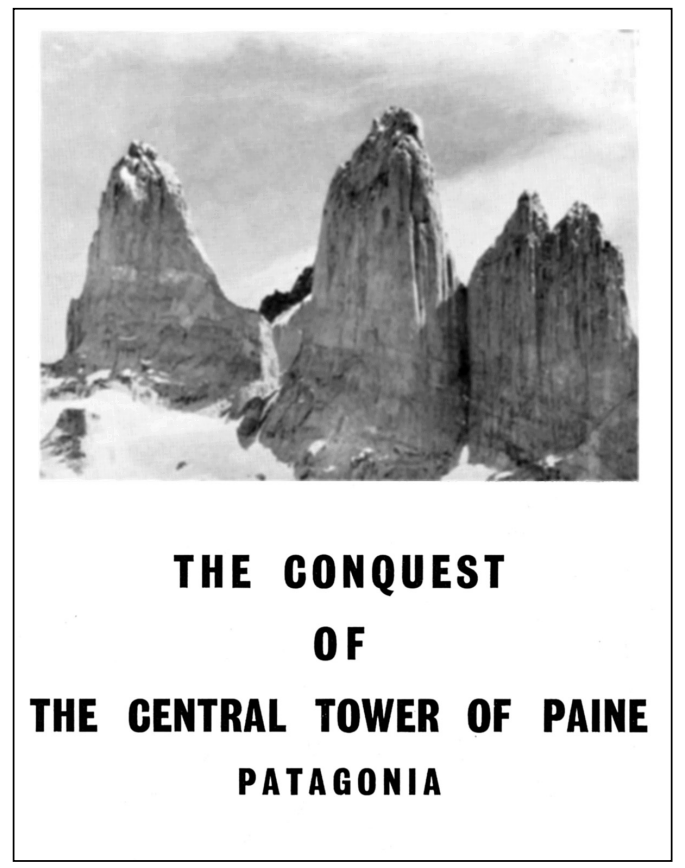


cumbre fue bautizada como "De Agostini", en señal de respeto y admiración hacia el más grande de los exploradores australes de todos los tiempos, que había fallecido en Torino cuatro años antes.

La difusión internacional de los éxitos conseguidos por los italianos y británicos durante los años sesenta, realmente la "época dorada" del alpinismo en el Paine, anima a la élite mundial de este deporte a seguir visitando el Macizo durante los 70 y los 80 , años en los que se irán completando las primeras ascensiones mundiales a las principales cumbres del sector.

$\mathrm{Al}$ margen de la indudable trascendencia deportiva con la que cuentan muchas de estas ascensiones, se debe destacarla la importante contribución que supuso, para el conocimiento geográfico y territorial del Paine, la difusión internacional de todas estas expediciones a través de la publicación de memorias y artículos, o la organización de exposiciones fotográficas y conferencias.

\section{CONCLUSIONES}

Los territorios patagónicos interiores, de Chile y Argentina, constituyeron un escenario geográfico prácticamente inexplorado hasta finales del siglo xIX, momento en el que los gobiernos de esos dos países comienzan a organizar una serie de expediciones científicas dirigidas, ex profeso, a establecer y demarcar los límites de sus respectivos territorios. En este contexto, las pampas, bosques y campos de hielo, que se correspondían con buena parte de los perímetros actuales de los Parques Nacionales de Torres del Paine y Los Glaciares, localizados respectivamente en territorio chileno y argentino, fueron unos de los muchos escenarios que fueron recorridos en diversas campañas, en ese caso, indudablemente, por la trascendencia que tenían estas grandes masas glaciares y sus cuencas drenantes a la hora de estrablecer el divortium aquarium.

Aunque resulta innegable la enorme importancia que todos estos viajes, indagaciones y estudios tuvieron en el descubrimiento y mejora del conocimiento geográfico de los territorios de la Patagonia, tanto en la Tierra de Fuego como en el interior del Continente, no es menos cierto que hubo otras muchas iniciativas que con posterioridad supusieron una nueva contribución en esa misma línea, aun siendo fruto de motivaciones y condicionantes bien distintos.

En este sentido, de todas las aportaciones a la mejora del conocimiento de la Patagonia interior y el sector del Paine que han sido consideradas en el texto, se debe destacar, por su trascendencia, la del salesiano italiano Alberto 
María de Agostini, viajero, montañista y geógrafo incansable que supo compaginar su sacerdocio con el estudio del territorio, ofreciendo al final de su vida un amplio legado documental, en forma de artículos, publicaciones, reportajes fotográficos y filmaciones.

En otro orden de importancia, resultaron también interesantes en el proceso de construcción y divulgación de la imagen de la Patagonia otros acontecimientos puntuales a los que también se refiere el artículo, concretamente: el primer viaje turístico a la Patagonia (1879), protagonizado por la aristócrata británica Florence Dixie, que dio lugar a la obra literaria Across Patagonia, o las sucesivas expediciones alpinísticas que tuvieron en el Paine su destino, que comienzan a producirse a partir de los años 30 del siglo pasado.

Por último, se llama la atención, por el carácter pionero y visionario de la iniciativa, sobre el rol desarrollado por el Touring Club de Magallanes y Werner Gromsh, su fundador y miembro más activo, en el primer conservacionismo de América del Sur y la Patagonia. La incansable labor desarrollada por este colectivo durante los años 30 del siglo pasado, tuvo su recompensa en la declaración, en 1959, del Parque Nacional de Turismo Lago Grey, germen del actual Parque Nacional de las Torres del Paine.

Recibido: 10/02/09

Aceptado: 30/03/09

\section{BIBLIOGRAFÍA}

A Través de la Patagonia. Traduc. M. T. Velasco y R. Martelli, Univ. de Magallanes, Punta Arenas (Chile), 1996, 254 p.

Ai Limiti del Mondo. A. M. De Agostini in Patagonia e Terra del Fuoco (1985). Cuadernos del Museo Nacional de la Montaña «Duca degli Abruzzi» y CAI, Torino, $221 \mathrm{p}$.

Bongiovanni, M. (1985): "Alberto De Agostini, un uomo su due coordinate. Ai limite del mondo". En: Alberto M. De Agostini in Patagonia e Terra del Fuoco. Cahier Museomontagna, Torino, pp. 13-27.

Braun Menéndez, A. (1969): Pequeña Historia Magallánica. Colección Cruz del Sur, $\mathrm{F}^{\mathrm{co}}$ de Aguirre, Buenos Aires, (5 $5^{\mathrm{a}}$ edic.).

Buscaini, G. y Metzaltin, S. (2000): Patagonia. Tierra Mágica para viajeros y alpinistas. Desnivel, Madrid, ( $1^{\text {a }}$ edic. en castellano), $304 \mathrm{p}$.

Coloane, F. (2000): Los pasos del hombre, Mondadori, Madrid, 275 p.

De Agostini, A. M. (1924): I miei viaggi nella Terra del Fuoco. SEI, Torino.

De Agostini, A. M. (1929): Mis viajes a la Tierra del Fuego. Edic. trad. de op. cit., Milán. 
De Agostini, A. M. (1934): Mi primera expedición al interior de la cordillera patagónica meridional. Buenos Aires.

De Agostini, A. M. (1935): La naturaleza de los Andes de la Patagonia Septentrional: Lagos Nahuel Huapi y Esmeralda. Soc. Edit. Intern., Torino.

De Agostini, A. M. (1945): Andes Patagónicos (2a edic.). Guillermo Kraft Ltda., Buenos Aires, 437 p.

De Agostini, A. M. (1946): Guía Turística de Magallanes y de los Canales Fueguinos. Sergio Body F. Edit., Punta Arenas, 151 p.

Díaz Bustamante, J. (1994): Crónicas de Última Esperanza. Fondo del Desarrollo de la Cultura y las Artes, Punta Arenas, 145 p.

Ferrer Jiménez, D. (2003): Conservación de la naturaleza y territorio en Chile. El Parque Nacional Torres del Paine y su área de influencia. Tesis doctoral. Departamento de Geografía de la Universidad Autónoma de Madrid. Director: Dr. Rafael Mata Olmo. Colección de tesis doctorales de la UAM.

Martinic Beros, M. (1985): Última Esperanza en el tiempo. Universidad de Magallanes (UMAG), $276 \mathrm{p}$.

Martinic Beros, M. (1981): Los alemanes en Magallanes. Instituto de la Patagonia, Punta Arenas, 52 p.

Martinic Beros, M. (1972): Magallanes, síntesis de Tierra y gentes. Edit. Fco de Aguirre, Buenos Aires, 195 p.

Mata Olmo, R. (2000): "Los orígenes de la conservación de la naturaleza en España". En: Estudios sobre el paisaje. Madrid, Fund. Duques de Soria, UAM ediciones, pp. 259-279.

Monzino, G. (1958): Italia in Patagonia. Spedizione patagoniche 1957-1958. Martello editore, 173 p. e ilust.

Pisano, E. (1974): "Contribución a la fitogeografía de la zona del Parque Nacional Torres del Paine. Estudio ecológico de la región continental sur del área andino-patagónica”. En: Anales del Inst. Patagonia, Punta Arenas, vol. V, nº 1-2, pp. 59-104.

Schwarz, A. (1985): "Alberto De Agostini e la naturaleza en la América Austral: una scheda". En: Ai limite del mondo. Alberto M. De Agostini in Patagonia e Terra del Fuoco. Cahier Museomontagna, Torino, pp. 73-80.

\section{RESUMEN}

El Parque Nacional de las Torres del Paine (XII Región, Chile), el Macizo Paine y su entorno, constituye un hito en la imagen de la naturaleza del mundo andino patagónico, en los inicios del primer conservacionismo de América del Sur y en los estudios científicos sobre esa parte del Planeta. En relación con ello, además, el Paine ha sido, desde su "descubrimiento" científico y viajero hace más de un siglo, un referente fundamental de las primeras propuestas de turismo de naturaleza asociado a la idea de la conservación y un reto de primer orden para las expediciones alpinas. 
Esas circunstancias explican que en la tesis doctoral del autor del presente artículo se dedicase un capítulo completo a analizar las principales aportaciones en el proceso de conocimiento geográfico de la Patagonia interior y construcción de la imagen de Torres del Paine como patrimonio natural a conservar. Sobre este tema versa precisamente este texto, en el que se aporta una información original sobre las exploraciones de reconocimiento geográfico que tuvieron lugar entre 1877 y 1896 en la Patagonia interior, por iniciativa de los gobiernos de Chile y Argentina; el primer viaje turístico conocido a la región chilena de Magallanes; el papel de los primeros "visionarios" del turismo andino-patagónico chileno, agrupados en torno a la figura de Werner Gromsh y el Touring Club; o la labor geográfica, científica y divulgativa desempeñada por el salesiano italiano Alberto Maria De Agostini. El artículo concluye con algunas consideraciones relativas a las primeras expediciones alpinísticas que tuvieron como objetivo las cumbres del Macizo del Paine.

PAlabras ClaVE: conocimiento; territorio; imagen; geográfico; turismo; exploración; aportación; conservacionismo; Paine; Patagonia.

\section{Abstract}

Torres del Paine National Park (12 ${ }^{\text {th }}$ Region, Chile), the Paine Massif and its surroundings are a major milestone concerning three issues: the perception of nature in the Patagonian-Andean environment, the first steps of conservationism in South America and the first scientific studies in this part of the planet. In addition, ever since scientists and travelers were to "discover" this region, Paine has been a benchmark of both the first proposals for nature tourism linked with conservationism, as well as a major challenge for alpine expeditions.

Due to these circumstances, the doctoral dissertation of the author devotes one entire chapter to analysing the main contributions of the Paine phenomenon to the geographical knowledge of inland Patagonia and to the perception of Torres del Paine as a natural heritage worth preserving. This is precisely the subject of this paper, which gives an insight into the geographical reconnaissance explorations that took place between 1877 and 1896 in the Patagonian inland, under the initiatives of Chilean and Argentinean governments; the first known touristic travel in the Chilean region of Magallanes; the role of the first "visionaries" of Patagonian-Andean tourism in Chile, gathered around Werner Gromsch and the Touring Club; or the geographical, scientific and informative work carried out by Alberto Maria De Agostini. Finally, the article discusses the first alpine expeditions which targeted the summits of the Paine Massif.

KEY WORDS: knowledge; territory; perception; geographical; tourism; exploration; contribution; conservationism; Paine; Patagonian.

\section{RÉSUMÉ}

Le Parc National Torres del Paine (XIIe Région, le Chili), le Massif Paine et son environnement, constituent un jalon dans l'image de la nature du monde andin patagoni- 
que, au début de premier conservationisme de l'Amérique du Sud et dans les études scientifiques sur cette partie de la Planète. À cet égard, le Paine a constitué en plus, dès sa "découverte» scientifique et voyageuse il y a plus d'un siècle, un point de référence fondamental des premières propositions de tourisme de nature associé a l'idée de la conservation ainsi qu'un défi de premier ordre pour les expéditions alpines. Ces circonstances expliquent que dans la thèse doctorale de l'auteur de cet article, un chapitre complet est dédié à l'analyse des principaux apports au procès de la connaissance géographique de la Patagonie intérieure et la construction de l'image de Torres del Paine comme héritage naturel à préserver. Ce texte porte notamment sur ce sujet, fournissant une information originale sur les explorations de reconnaissance géographique qui ont eu lieu entre 1877 et 1896 à la Patagonie intérieure, de l'initiative des gouvernements du Chili et l'Argentine; le premier voyage touristique dont on a connaissance à la région chilienne de Magallanes; le rôle des premiers "visionnaires" du tourisme andin-patagonique chilien, regroupés autour de la figure de Werner Gromsh et le Touring Club; ou l'œuvre géographique, scientifique et de divulgation réalisée par le Salésien italien Alberto Maria De Agostini. Larticle conclut avec quelques réflexions relatives aux premières expéditions alpinistiques qui s'étaient fixé pour objectif l'ascension des sommets du Massif del Paine.

MotS CLÉs: connaissance; territoire; image; géographique; tourisme; exploration; apport; conservationisme; Paine; la Patagonie. 